\title{
Children's Narratives of Family Life in Ghana: A Cultural Lens via Story Stems
}

\author{
Nadine M. Hosny ${ }^{1} \cdot$ Adam Danquah $^{1} \cdot$ Katherine Berry $^{1} \cdot$ Ming Wai Wan $^{1}$ \\ Accepted: 31 August 2020 / Published online: 12 October 2020 \\ (c) The Author(s) 2020
}

\begin{abstract}
A Western worldview pervades the social and psychological study of children. The current study employed a story-stem method to qualitatively explore the daily and family life experiences of young Ghanaian primary school children in urban Ghana through their story narratives. The recorded narratives of 695 - to 8-year-old children were elicited through presenting stems of common child-caregiver scenarios and thematically analysed. Five overarching themes were identified: daily routines and concerns, child-caregiver interactions, spirituality, death-related fears and depictions, and responses to injury. The narrative themes reveal the likely mental and physical occupations of these children, as characterized by household chores, financial concerns and school concerns, as well as underlying cultural values through their portrayals of parenting values, parental discipline and spiritual beliefs. Story stems depicting common childhood problems (e.g. knee injury) sometimes evoked death and hospitalization subthemes following an escalation of health problems. Possible interpretations for these findings are discussed, taking into account cultural, developmental and emotional factors. Story stems are a promising and developmentally appropriate tool for qualitative analysts to investigate the experiences and worldview of young children in non-Western cultures.
\end{abstract}

Keywords Story stem methods $\cdot$ Qualitative $\cdot$ Africa $\cdot$ Thematic analysis $\cdot$ Caregiver-child interaction

\section{Highlights}

- Children's daily-life accounts provide a window into life experiences, beliefs, coping strategies, and empathic understanding.

- Children's story stem narratives reveal understanding of culturally-embedded values; e.g. family duty, spirituality, and caregiver discipline.

- Children perceive their caregiver's instrumental support as a form of affection and emotional care.

- Story stems are a developmentally appropriate tool for qualitative explorations of culturally-mediated experiences.

Over the past two decades, there has been increasing interest in the integration of children's 'voices' into crosscultural and developmental research. Children's narratives offer first-hand perspectives of family life through

Supplementary information The online version of this article (https:// doi.org/10.1007/s10826-020-01839-6) contains supplementary material, which is available to authorized users.

Ming Wai Wan

M.W.Wan@manchester.ac.uk

1 School of Health Sciences, University of Manchester, Manchester, UK understanding their worlds, including subcultures of childhood on the one hand, and the wider cultural context, on the other (Lansdown 2004). Developmental and family studies have increasingly incorporated the voices of child participants, yet children's voices still almost exclusively receive representation from the Western cultures that dominate the behavioural and social sciences (Keller and Kärtner 2013; Weisner 2005). This inevitably undermines the potential value of children's narratives as portals to existing sociocultural scripts beyond or aside from Western frameworks (Harwood et al. 1997; Tamis-LeMonda et al. 2008).

A method that has been used clinically and in research with young children to access their internal mental scripts and social experiences is the story stem method. This 
semi-structured method involves presenting standard story scenarios that are usually familiar and evocative to the child and asks the child to create a narrative completion. Storystems have now been well used in research for studying a range of personal and family-based constructs embedded in social contexts from young children's perspectives, including child-parent attachment representations (e.g. Allen et al. 2018), interparental interactions (e.g. Castrechini Fernandes Franieck and Page 2017), family instability (e.g. Coe et al. 2017), emotion regulation (Batki 2018), aggression (e.g. Arsenio and Ramos-Marcuse 2014), and family and disease-specific beliefs (e.g. Winter et al. 2011).

Story stems likely lend themselves to understanding children's thoughts and feelings in different cultural contexts. Firstly, story-telling is universal; from a young age, stories are used to transmit cultural knowledge and to allow children to communicate details about their lives with decreased inhibition (Plokar et al. 2017). Secondly, young children tend to struggle to express themselves well and openly with direct interview methods and may be more amenable to indirect methods like story stems. Through presenting relatable scenarios to children, they are invited to participate in a creative storytelling process that is understood to tap indirectly into their cognitive scripts, memories, representations of self in relation to others, unconscious emotions, and/or behavioural tendencies based on lived experiences and cultural perceptions (Clarke et al. 2017; Milojevich and Quas 2017; YuvalAdler and Oppenheim 2015). The typical and everyday-like nature of the situations between children, and their caregivers allows this technique potentially to be employed within different socioeconomic contexts, as well as in diverse ethnic and cultural settings (Robinson et al. 2000; Dealy et al. 2019). Furthermore, indirect methods such as story stems may be particularly suitable for use in hierarchical societies in which adult-child power disparities typically encourage conventional or conformist responses to adult questioning (AdzahlieMensah 2014).

Although story-stem completions are often analyzed quantitatively by applying coding or rating schemes, qualitative methods can also be applied specifically to the narratives produced, which may suit the cross-cultural exploration of content themes that arise without imposing prespecified coding frameworks that likely carry inherent culture-specific assumptions. A qualitative approach also allows the researcher to benefit from the contextual richness of the child's meaning-making of their family or social worlds via storytelling that is often lost in quantitative approaches (e.g. Castrechini Fernandes Franieck and Page 2017).

Our current study focuses on children in Ghana, a developing West African nation with 31 million citizens (United Nations 2019). Ghana was a British colony from 1874 until 1957, known then as the Gold Coast. British influence upon the culture, education, and legal system is still reflected in modern day Ghana (Dowden 2014). The country's official language is English, although 50-100 local languages and dialects are spoken represented by many ethnicities (Quist 2003). The people of Ghana are considered highly heterogeneous in cultural, linguistic, and spiritual practices. While Ghana is comprised of heterogeneous groups, salient communal values characterize Ghanaian sociocultural heritage such as mutual aid, obedience, and reciprocal obligation (Twum-Danso Imoh 2013). Accra, the capital, exhibits influences from residents and families drawn from different ethnic groups, who move to the urban capital seeking economic and political opportunities. In common with many African nations, recent decades have seen significant economic development which has led to changes in family and living conditions, especially in urban areas (Arku et al. 2011; Ghana Statistical Service 2014; Owusu and Afutu-Kotey 2010; Sam 2001). However, despite urbanization efforts and the enhancement of living conditions over the past decade, inequality continues to increase (Cooke et al. 2016). Almost a quarter of inhabitants in Greater Accra live in poverty. Furthermore, children are at forty percent more risk of living in poverty than adults (Cooke et al. 2016).

Aside from the macro contexts of health and economic development, contemporary family life in urban Ghana is very little represented in academic literature. Although traditionally Ghanaian society was characterized by the extended family system, in which child-rearing was a communal practice, economic changes and Western influences brought by globalization have now paved way for the rapid emergence of the nuclear or small family system, where responsibility of child-rearing falls mainly on their immediate caregivers (Boakye-Boaten 2010), parents who move to urban cities for economic reasons depend on social institutions like schools, church, and the media instead of extended families act as 'surrogate' caregivers (Akyeampong and Stephens 2002; Kuyini et al. 2009; Nyarko 2014). Despite the pace of demographic change, children continue to be raised to view themselves in relation to their relatives and community (Sam 2001; Boakye-Boaten 2010) and emphasis is placed on cultivating children's sense of belonging and relatedness with others. Parenthood is viewed as the opportunity to train and instill Ghanaian values, such as reciprocity, responsibility, respect, honesty, humility, sense of obligation and the fear of God (TwumDanso Imoh 2013).

Ghanaians are also known to be deeply spiritual and spend a considerable amount of time attending religious functions, begin their non-religious meetings with prayers, and show their religious devotion in every sphere of life including marriage, education, economic affairs, politics, and parenting (Okyerefo and Fiaveh 2017). Religion has a 
strong influence on parenting style and goals, reflecting the intrinsic nature of socio-religious life in Ghanaian culture (e.g. Okyerefo and Fiaveh 2017). Parenting and formal education in Ghana focus on obedience as a core value to facilitate children's learning of all other values (TwumDanso Imoh 2013). Children's subjective experiences are likely shaped by their sociocultural reality, yet very little is known about young Ghanaian children's perceptions of and beliefs and values permeating their daily life.

The current study is a qualitative thematic analysis of narratives produced by Ghanaian primary school aged children based on story-stems of daily family life in urban Ghana. By utilizing an inductive approach to analyze the narrative content produced by young children, the current study aimed to interpret young children's 'voices' without imposing any coding frameworks to direct the focus of the study. This study is a secondary study based on data originally collated to test the utility of this set of story-stems in this sample. Story-stems were combined with a validated coding scheme used as a quantitative measure of child attachment representations in a non-western context (see Wan et al. 2017). The previous study found that all childparent attachment classifications were represented in the Ghanaian sample (73 percent was securely attached). Findings were based on observational (videotaped) evidence from the child's play, narrative (coherence and content) and behaviour that inform a series of rating scales. Further, the study noted nuances in some children's responses that did not fit in typical ways into the MCAST coding scales (e.g. representations of child-caregiver proximity seeking were seen but seemed to be to relay information rather than explicitly seek comfort; representations of caregiver emotional warmth were less common in otherwise responsive caregivers), and may reflect cultural attitudes and values, and the ecological setting in Ghana. The current study focused on all forms of insight (i.e. not on attachment-related information per se) gained from children's narrative content (not behaviour). The focus was on overall narrative content that provides contextual (i.e. culturally mediated) information, reflecting children's perceptions, experiences, beliefs and values in everyday life. This offers a valuable and novel glimpse into the lives of young Ghanaian children and provide a cultural perspective that has been rarely documented.

\section{Methodology}

\section{Sample and Context}

In Accra, the capital of Ghana, over 90 percent of schoolage children attend school, which is compulsory up to the age of 15 years (Fink et al. 2012). English is the language of instruction. In this region, both private and public schools are commonplace, with 918 public primary schools and 1168 private schools in Greater Accra (Republic of Ghana Ministry of Education 2013). Private schools account for $29 \%$ of all Ghanaian primary schools (2012/2013), and are experienced by two thirds of children in peri-urban areas of Greater Accra (McCullough et al. 2015). However, the terms 'private' and 'public' must be placed in a relative context; for example, not all private schools have access to drinking water or have toilets $(93 \%$ and $94 \%$ respectively in Greater Accra). We actively sought the participation of both types of primary school in order to obtain daily life narratives that would be relatively representative of the socioeconomic diversity of urban Ghana. Participation to the study was invited through schools who printed letters for children to take home to show their family-the usual mechanism through which schools communicated official information to students' families. No incentives were provided for schools', children's' or caregivers' participation, with the exception of offering drinks and snacks for caregivers attending one of two optional meetings offered to discuss the project and complete basic questionnaires with the researchers. These meetings were offered to target caregivers who were unable to read or had very limited reading competence and therefore could not have understood the invitation letter or provide informed consent via written material. As we recruited through schools, the voices of children from the most difficult backgrounds (e.g. living below the poverty line, less engaged caregivers, or with no sufficient English language proficiency to read), who were likely to be occasional or non-attenders, were likely to be excluded. However, based on anecdotal evidence from the public school, many families were motivated for the child to attend school to ensure the child received at least one meal a day (i.e. a free school meal).

English-speaking children, aged between 5 and 8 years, were recruited from a private and a public primary school in the Greater Accra region, Ghana. Informed consent was obtained from the parents or caregivers for $\mathrm{N}=76.7$ were excluded from analysis $(\mathrm{N}=7$ due to poor audio quality and $\mathrm{N}=1$ had lived in the United States for a long period), resulting in a final sample of $\mathrm{N}=69$. Our sample consisted of $38(55 \%)$ girls and $31(45 \%)$ boys with a mean age of 7.22 years $(S D=0.95$ years). $\mathrm{N}=31(45 \%)$ children were recruited from a public school and $38(55 \%)$ from a private school, distributed as follows: $23.2 \%$ in Year 1, 50.2\% in Year 2, and 26.1\% in Year 3. Although we sought to recruit children from 5 years of age, many Year 1 students were in fact older (than stated in official records) and had started school later, while some lacked confidence in their English competence, despite all school instruction being in English. The primary caregiver, to be depicted in the story stem, was identified as: $79.7 \%$ mothers, $5.7 \%$ grandmothers, $4.4 \%$ 
fathers, $7.3 \%$, aunts; older sibling 2.9\%. Highest occupational status in household was distributed across the sample as follows: 9 (13\%) professional or managerial, 25 (36.2\%) skilled manual, 14 (20.3\%) semi-skilled and 21 (30.5\%) unskilled.

\section{Measures and Procedure}

The Manchester Child Attachment Story Task (MCAST; Green et al. 2000) is a validated story-stem and doll play method that comprises two components, a 'story stem' procedure and a coding scheme for classifying attachment (see Allen et al. 2018). The current study utilised only the procedure, which presents four semi-structured scenarios or 'stems' that were likely to be familiar to young children (having a nightmare, hurting your knee, having a stomachache, and getting lost). This procedure was designed to elicit story completions from which, in the original MCAST measure, the child's attachment classification is usually evaluated. However, as children create stories from these stems (free responses with non-leading prompts from the interviewer), there is potentially rich contextual information that is captured beyond attachment-specific information. The story-stem scenarios mainly take place in the home, as represented by a doll's house, and dolls are taken to represent the child (e.g. "Isabel-doll") and caregiver (e.g. "Auntie doll") who are present in each story-stem. The same four story-stems were used in the current study after minor adjustments were made to the story stems to ensure cultural relevance, mainly in the use of appropriate dollhouse props to match more closely Ghanaian homes (e.g. most of the furniture was removed, the stove was replaced with a large pot), script amendments to accommodate vernacular expressions (e.g. "pain in his stomach" instead of "stomach ache"), as well as changing locations to culturally relevant ones (e.g. market in place of shopping centre, for further details see supplementary materials and Wan et al. 2017). Non-leading prompts are used to encourage a more complete response and standard probes address the feelings and thoughts of the child and the caregiver.

The story stems were administered by a single administrator in school in a private room or space that was also familiar to the child, with no other people present. The administrator first asked the participant about who "mainly" took care of them at home and engaged the child with the doll's house and props to establish rapport and find out their primary caregiver to be referred to in the story stems). A practice (control) story-stem ("Breakfast") was used prior to the 'test' stems to familiarize the child with the task and enhance rapport. Each story stem task lasted for an average of $15 \mathrm{~min}$, ranging $10-25 \mathrm{~min}$. Separately, parents completed or were administered a brief questionnaire on basic sociodemographic and family background characteristics.

\section{Thematic Analysis}

Qualitative thematic analysis (TA) provides researchers with the flexibility and theoretical freedom to inductively explore recurrent patterns of children's meaning-making, without being confined to pre-set and limiting coding frames or particular themes (Braun and Clarke 2006; Guest et al. 2011). TA allows for a rich description of the dataset in relation to a broad research aim to gain a cross sectional view of experiences related to the children's perspectives of family and cultural life (Braun and Clarke 2006; Braun et al. 2017).

Independent verbatim transcriptions of videotaped storystem completions were analysed for content themes using QSR NVivo 11 software to manage the categorization of data and search for recurrent words. Data analysis and interpretation followed the guiding framework for TA proposed by Braun and Clarke (2006). Transcripts were coded using an open "data-driven" approach guided by the team, and an inductive process was employed whereby small units of data were scrutinised, interpreted, and grouped into themes, following an iterative process until all categories of meaning are exhausted. During refinement of themes, data were reviewed on two levels: (1) Coded extracts were reviewed against the themes, which were refined at points when data extracts were not aligned with proposed themes; (2) After code consolidation and dissolving particular themes the thematic map was reconceptualised. Codes were also organised into overarching themes and subthemes. Finally, narrative flow, coherence, and meaning of selected supporting extracts were reviewed.

All initial coding was carried out by a psychology postgraduate $(\mathrm{NH})$ with some training in qualitative methods and of thematic analysis from other co-authors (the supervisory team). Following initial coding, the output was discussed thoroughly with the supervisory team of developmental and clinical psychologists with qualitative research experience and expertise in studying children, cultural psychology and the MCAST (AD, MWW, KB). The following measures were taken to ensure quality and rigour: (1) the thematic analysis was conducted blind to all child and family background information; (2) a reflexive approach and $\log$ were utilized throughout the analysis process; (3) analysis was completed in regular consultation with the other authors; the operational description of codes was discussed and a refined coding frame was jointly finalized to ensure coding frame transparency (Joffe 2012).

\section{Results}

Five overarching themes were identified from children's narratives: daily routines and concerns, child-caregiver interactions, spirituality, death related fears and depictions, and 
Fig. 1 Thematic map of children's narratives of family life

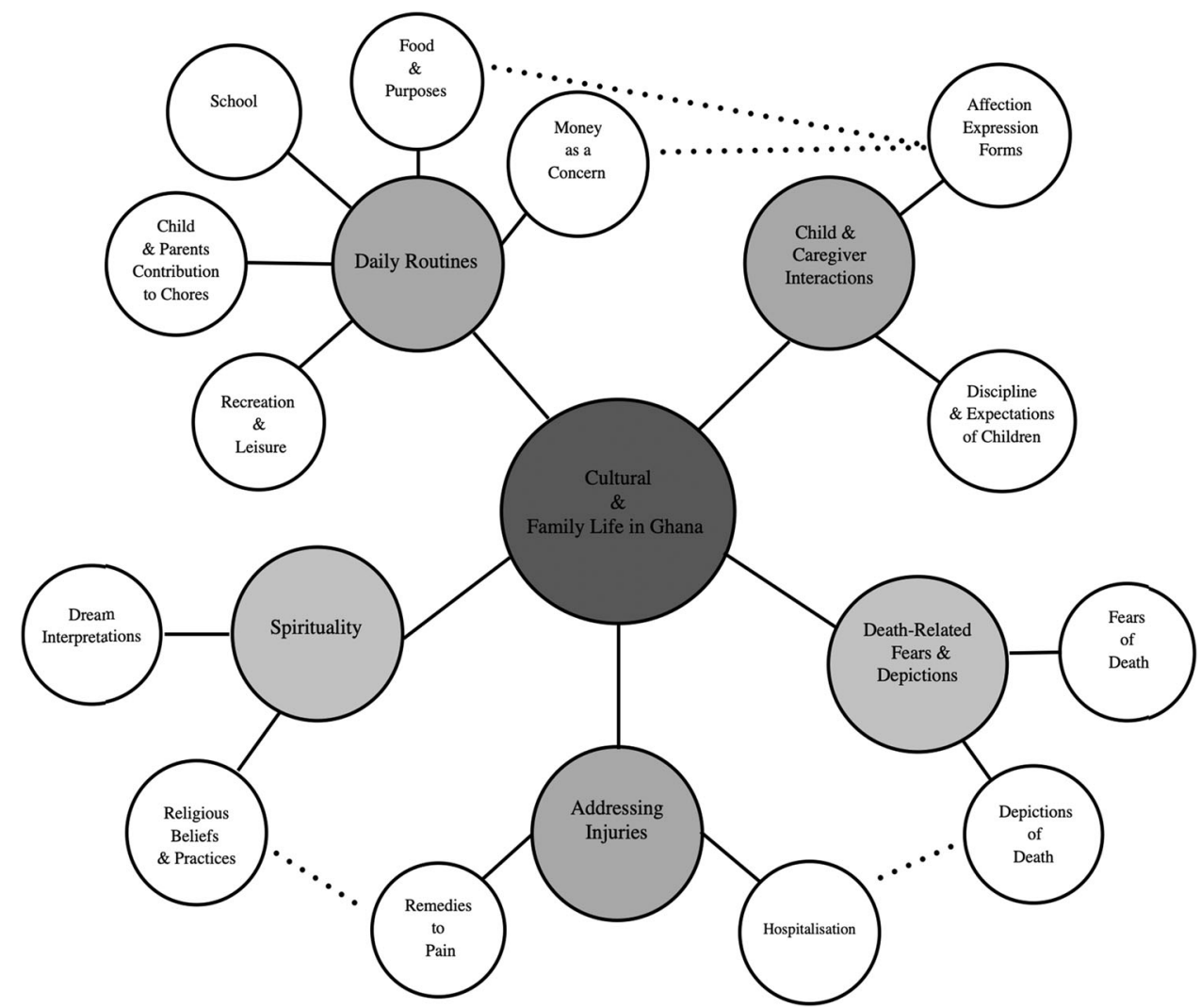

finally choices to address physical injuries (Fig. 1). Each theme, with their subordinate themes, are described below, and excerpts used to ground extracted themes into the experiences of children and to portray similarities and variations in accounts within themes Table 1.

\section{Daily Routines and Concerns}

The daily routines and concerns theme covers everyday life encompassing going to school and money concerns as subthemes that children raised spontaneously, while household chores, recreational activities, and sharing mealtimes had been introduced or prompted in the story stems.

The school subtheme (24.6\%) typically described the caregiver instructing the child, or the child thinking about, getting ready to go to school. Some narratives described the caregiver reprimanding the child for not attending or for being late to school or monitoring their studies.

She [Mother] call A-doll "Every day you are going to school, but you don't wake up!" And she told A-doll wake up! [Girl-7Y-Getting Hurt Stem]

Other narratives described caregivers articulating their academic aspirations for the child: e.g. "get first of class in school" [Girl-8Y-Nightmare Stem]; "She [Mama-doll] is thinking that $\mathrm{K}$-doll to be a doctor" [Boy-8Y-Stomachache
Stem]. Such narratives may demonstrate the caregiver expressing a desire for the child to make their family proud or for financial help, or otherwise may reflect a form of indirect praise of the child's abilities-all of these interpretations suggest a certain relational inter-dependence, and each link with other (sub)themes.

Another unprompted subtheme raised by $15.0 \%$ of children was money concerns, usually expressed as the caregiver and/or child having limited or no purchasing power, often with a sense of helplessness or sadness. Children were highly conscious of the family's financial needs for food, school fees, hospital fees or 'better' housing. Some narratives attested to the child's preoccupation with obtaining money for the caregiver, though how was less clear. In other narratives, the child's own desire to buy goods was overlooked by caregivers to spend the limited money amounts on essentials:

Then E-doll told her that she wants to buy this and Aunty-doll said there is no money. The money she had she use to buy food for E-doll. [Girl-6Y-Getting Lost Stem]

G-doll said "give me money to go to school" And father go say he don't have money. [Girl-8Y-Getting Hurt Stem] 
Table 1 Number (\%) of children whose narratives contained extracted subthemes $(\mathrm{N}=69)$

\begin{tabular}{|c|c|c|}
\hline Themes & $\mathrm{N}$ & $\begin{array}{l}\text { Subtheme appears in the } \\
\text { story stem scenario }\end{array}$ \\
\hline \multicolumn{3}{|l|}{$\begin{array}{l}\text { 1. Daily routines and } \\
\text { concerns }\end{array}$} \\
\hline 1.1 School & $17(24.6 \%)$ & No \\
\hline 1.2 Money & $10(15.0 \%)$ & No \\
\hline 1.3 Household chores & $22(31.8 \%)$ & $\begin{array}{l}\text { Yes (by the } \\
\text { caregiver only) }\end{array}$ \\
\hline 1.4 Mealtimes & $69(100 \%)$ & Yes \\
\hline $\begin{array}{l}\text { 1.5 Recreation activities } \\
\text { 2. Child-caregiver } \\
\text { interactions }\end{array}$ & $69(100 \%)$ & Television, outdoor play \\
\hline $\begin{array}{l}\text { 2.1 Explicit affection } \\
\text { expression }\end{array}$ & $17(24.6 \%)$ & No \\
\hline $\begin{array}{l}2.2 \text { Implicit affection } \\
\text { expression }\end{array}$ & $30(43.5 \%)$ & No \\
\hline $\begin{array}{l}\text { 2.3 Punishment } \\
\text { 3. Conceptualisations } \\
\text { of death }\end{array}$ & $23(33.3 \%)$ & No \\
\hline 3.1 Contexts of death & $20(28.9 \%)$ & No \\
\hline $\begin{array}{l}\text { 3.2 Concerns about death } \\
\text { 4. Spirituality }\end{array}$ & $12(17.4 \%)$ & No \\
\hline 4.1 Prayer and church & $21(30.4 \%)$ & No \\
\hline $\begin{array}{l}\text { 4.2 Dream interpretation } \\
\text { 5. Healthcare choices }\end{array}$ & $10(15.0 \%)$ & Nightmare \\
\hline $\begin{array}{l}\text { 5.1 Pain remedies/ } \\
\text { medication }\end{array}$ & $44(63.8 \%)$ & $\begin{array}{l}\text { Stomach pain, falling } \\
\text { over/hurt knee }\end{array}$ \\
\hline 5.2 Hospitalisation & $32(46.4 \%)$ & $\begin{array}{l}\text { Stomach pain, falling } \\
\text { over/hurt knee }\end{array}$ \\
\hline
\end{tabular}

While household chores were present in the content of two story stems as duties undertaken by the caregiver (cleaning in one stem, cooking in another) during which the child is otherwise occupied (watching television, playing outside), $31.8 \%$ of the sample described an array of household tasks, including cleaning, washing dishes, tidying up, laundry, and helping caregivers while cooking, all of which the child was generally expected to complete. Children undertaking such duties often appeared in response to stems not containing these themes. Household tasks were sometimes done to please the caregiver when the caregiver was otherwise preoccupied, or were not completed, leading to disciplinary action:

She clean all the house before her Mama come. [...] She feel when her mother comes she will say her "good working". [...] Mama came. He press the button (doorbell) "Yes, mummy! Mummy!" "Wow! and says to her "good working". [Girl-7Y-Getting Lost Stem]
So, A-doll was crying she did not do the work that Mama-doll said and she went and sleep again. [...] And Mama-doll saw her sleeping and she came down and she took cane and she came. [Girl-8YNighmare Stem]

Narratives describing the activities of adult caregivers were dominated by domestic duties, doing them or thinking about them. Mothers or female caregivers, in particular, were mostly consumed by their chores.

S: ...She [Mother] is thinking that she should wake up and go and cook some food.

R: But, she just cooked some food.

$\mathrm{S}$ : She is thinking she can wash some clothes, arrange the room and sweep. [Girl-7Y-Getting Hurt Stem]

Mealtimes and recreational activities were prompted or present in at least one story stem by all our sample, which firstly demonstrated their ability to stay on task and secondly, appeared also in response to stems in which these themes were not prompted or present. Story descriptions included the routines of meal preparation, and the functions of food and eating, bringing family together on a regular basis. Food or being provided with food by the caregiver was a source of comfort for almost every child in situations of distress:

I: I-doll says I have hurt. And she [Mama-doll] took Idoll inside. [...] And Mama-doll went to cook. After cooking she went and call I-doll. And she said to Idoll we'll eat here. [Kitchen]

\section{R: How is I-doll feeling? How is I-doll's knee?}

I: It was fine and Mama-doll say, how is your leg? And she say "it's fine." They went to the sitting room and Mama-doll say, "How is your leg?" she says "It's fine" They went sitting room and ate'. [Girl-7YGetting Hurt Stem]

Outdoor activities, prompted by one stem, led to boys mainly playing football and girls mainly 'ampe' (a skipping game). Indoors, two children mentioned reading, and most children described the child and adults watching television (which is introduced in one stem). Television also sometimes served as a distraction from distress or a consolation after overcoming distress. 


\section{Child and Caregiver Interactions}

Narratives involved various types of child-caregiver exchanges and interactions. Implicit forms of affection were expressed by $43.5 \%$ of participants, most typically through caregiver gestures, such as the giving of food, gifts, allowances etc. After times of child distress, parents allowed the child to buy desired items, or caregivers provided children with food or gave them money as presents. In statements such as "Mama cook nice food. [...] she is thinking about she likes her child very much." [Girl-8Y- Getting Lost Stem], these actions seem to represent acts of affection comprehended by children. Children in turn were described as reciprocating such actions by expressing future aspirations to provide desired objects to caregivers when financially capable:

L: Feel that one day if his parents buy camera for him, he will be happy, so he said when he grow he will buy a camera for the mother and he will go and teach the mother how to drive. One day he will be happy that his mother has a car.

\section{R: How was Mama-doll feeling about this?}

L: Mother-doll feel that she is happy, say that she likes the son.[Boy-6Y-Getting Lost Stem]

Explicit forms of affection were expressed by fewer children $(24.6 \%)$ than implicit forms, some of which were explicit verbal of physical forms of affection, and others were implicit gestures. Caregivers embracing their child during or after times of distress were the most common form of explicit affection, perhaps followed by expressions of sympathy and worry. Some children's narratives suggested a high awareness of caregiver empathy, as caregivers were 'sorry' [Boy-8Y-Getting Hurt Stem] or 'feeling for her child" [Girl-7Y-Stomachache Stem] or "thinking about what is paining her child" [Boy-6Y]. However, only one child used explicit verbal affection (i.e. 'love') in their narrative.

A second subtheme concerned disciplinary consequences or punishment as a result of not complying with the caregiver's behavioural expectations of the child. $33.3 \%$ of the narratives emphasized child obedience and compliance, even when the child was described in the narrative as noncompliant, indicative of the child's understanding of expected behaviour and the consequences for noncompliance:

He feel that Mother tell you something, then if you don't do it, your mother will be angry with you....
Because E-doll didn't obey her.' [Boy-8Y-Getting Hurt Stem]

Punishment followed from children breaking this code of conduct, including when children cause caregiver worry by jeopardising their own wellbeing or safety. While verbal discipline was sometimes described, physical punishment and fear of such punishment was also represented, usually expressed as "beating" or "caning". Children's narratives included feeling afraid or sad following physical punishment, yet never as retaliatory or aggressive, and sometimes included attempting to avoid punishment through apologizing or hiding:

...She said "A-doll wake up!" and A-doll does "Ahhhh" [Stretching arms] So, she said "Mama, I am feeling sleepy." And Mama-doll go and beat her and A-doll was crying. And she said "Don't you hear I said wake up!" [Girl-8Y-Nightmare Stem]

...She is thinking that when he fall his mother would beat her. So, she is praying that her mother don't beat her. [Girl-6Y-Getting Hurt Stem]

Some included caregivers expressing remorse and regret after giving physical punishment, suggesting an insight into the child's understanding of caregiver empathy and, in this case, revealing a nuanced appreciation of differences between actions and feelings:

G: She is about to cry she doesn't wasn't grandmother-doll to cane her, because when grandmother-doll went to the market she was hungry, so she took the food.

\section{$\mathrm{R}$ : What is Grandmother-doll feeling?}

G: Grandmother-doll also feel sorry for her not to beat her granddaughter, because she know that when she went to the market she [Grandmother] did not give her food to eat before she went. [Girl-8Y-Getting Lost Stem]

\section{Death-Related Fears and Depictions}

This theme addresses the variety of contexts in which children mention death, and the concern and worry expressed by both caregivers and children regarding death. With regards to contexts (28.9\%), death was present in 
accounts narrating seemingly realistic events and in the dreams and fears of children and caregivers. Although two of the contexts in which death themes often occurred may have been influenced by specific story stem content (child has a nightmare; child has stomach pain while watching television), a wide range of narratives are typically described by children using the MCAST and the stems are unlikely to specifically prime for death themes. Children described dreams that centred around parent abduction and/ or murder and/or less frequently, the caregiver was described as having this kind of dream:

"He was dreaming about somebody was going to come and, cut his head. [Boy-7]

... And Mama-doll dreamed a bad dream that her child was take and she died. And she [Mama-doll] too she dead. [Girl-8Y-Nighmare Stem]

While a link between nightmares and death may reflect implicit views on spirituality (discussed later), the 'stomachache' story-stem often evoked narratives of child hospitalisation from which death was one outcome:

E: Mum, take me to the hospital my stomach. [...] She hold her mother and her mother take her to the hospital and he put her in the bed. "Are you okay? Are you okay?" and E-doll die. [Girl-8Y-

Stomachache Stem]

Furthermore, accidents, such as traffic accidents, were sometimes described to result in death of the caregiver. One child described how, after putting groceries away in a cupboard at home, a piece of furniture fell on the parent's head, and the child finds the parent dead, perhaps reflecting the child's emotional landscape and/or fears.

A second subtheme, concerns about death (17.4\%), reflected children's descriptions of fear of caregiver or child's death: "She [caregiver-doll] is praying she don't want E-doll to die." [Girl-8Y-Stomachache Stem]. Such concerns often followed a negative event, such as suffering from a minor injury, although none of the story stems prompted death as a consequence of any injury or distress. A few participants expressed worry about a parent's death after distressing situations that do not appear to have an obvious threat, such as after being lost at the market: "E: She is thinking about her mother... to not die." [Girl-8Y- Getting Lost Stem] or, when prompted for their thoughts, some expression of concern in other accounts is provided seemingly out of context that the child "is thinking about her mother not to die" [Girl-8YGetting Hurt].

\section{Spirituality}

The spirituality theme describes religious practices and beliefs $(30.4 \%)$ and the belief in and value given to interpretation of dreams $(15 \%)$ - the latter perhaps prompted by the 'bad dream' story stem.

A key religious practice that was portrayed was prayer; children incorporated prayer in conversations of daily life at times of eating and sleeping, and most commonly at times of physical or emotional distress in children and caregivers, such as for preventing further harm or alleviation of pain. Concerns about money were also incorporated in prayer, more commonly expressed by caregivers. Other children described prayer perhaps for seeking and giving comfort, such as 'God, will bless him and him knowledge and wisdom.' [Boy-6Y-Stomachache Stem], or after a nightmare:

R: How is Mama-doll feeling? How is she feeling on the inside?

C: She feel sad, but she tell C-doll don't worry, be happy, don't cry. I will send you to church so, you can pray. Mama-doll say C-doll "Don't worry your dream will go, and you dream about Jesus and he bless you."

\section{R: How is he Feeling?}

C: He's feel okay, he happy that he will dream a good dream. [Boy-6Y-Nightmare Stem]

Attributing power to prayer for assuaging distress was vital in understanding expressed beliefs of children about prayers and their ability to extend from spiritual purposes to tangible manifestations in daily life. Children often expressed prayer as having an immediate effect on enhancing conditions or preventing negative consequences, which at times seemed to be favoured over medication or other solutions:

...She is thinking that "Oh, Lord I pray for you that Edoll do not die. Oh, Lord you are so good. E-doll do not die." [Girl-8Y-Stomachache Stem]

Mama-doll is thinking that $\mathrm{C}$-doll hands will not break again and Mama-doll pray for C-doll. And nothing happens to C-doll again. [Girl-8Y- Getting hurt Stem]

Church attendance was described by some children as part of their weekly routine. Some narratives occasionally 
referred to heaven as a happy 'place' and one in which desired material needs are met:

Mama-doll is thinking she has no radio, so when she goes to heaven God will give her all the things that she need. [Girl-7Y-Getting Hurt Stem]

Dreams interpretation was a second subtheme (15.0\%), most notably the child or caregiver perceiving dreams to have implications for reality, and they often sought to interpret them.

He [Mama-doll] is feeling that my dream was a bad dream and something can happen to her daughter [Girl-8Y-Nightmare Stem]

Children indicated that caregivers were more capable of such interpretations, and protection from the realization of dreams content was also assigned to caregivers. Caregivers resolved to religious practices such as prayer, indicating that the belief in the value of dreams was intertwined with other religious beliefs:

K: I don't know. Maybe my mother knows.

R: Bad things or good things?

K: Bad things.' [Girl-7Y-Nightmare Stem]

They were talking about the dream and E-doll say in the dream Satan wanted to kill me [...] Mama-doll is praying that she will not dream that again. [Girl-8YNightmare Stem]

\section{Addressing Injuries}

Healthcare issues arose that perhaps reflected two of the story stems that focus on pain (child has a stomachache; child falls over and hurts knee). Almost half of the children expressed that the caregiver responded to the pain or injury with some sort of medical aid to alleviate the pain, such as providing a plaster (band-aid) for a hurt knee, often followed by some brief indication of improvement. Other responses involved turning to comforts or distractions to cope with the pain, such as television, food, and sleep. Almost half of the narratives included hospitalization, which sometimes linked to the aforementioned concerns of the child dying:
E: And then her mother come. She shout and say "What happen? What happen?" She say when she go play 'Ampe' she jump and she fall and she hurt. And E-doll's mother take her to hospital.

\section{$\underline{\mathrm{R}:}$ What happens next?}

E: She [Mother] say "Doctor, Doctor my child is dying" And the doctor looks at the child's eyes. And the doctor said "go tomorrow you will come and pick her" [Girl-8Y-Getting Hurt Stem]

\section{Discussion}

The current qualitative study of children's story stem narratives produced a broad range of narrative themes that seem to be imbued with the lived experience and emotional concerns of young school-age children growing up in contemporary urban Ghana. Five key themes were identified in our sample: daily routines and concerns, close interactions with caregivers, death conceptualizations, spiritual beliefs and practices, and healthcare-related responses-each with distinct subthemes. The findings may be taken to support the utility of this 'child-centred' method in a cultural context in which more socially hierarchical and collectivist values seemed to be operating in Ghana. However, when considering the 'validity' of story stems in different cultural contexts, a crucial point is that our employment of this indirect method was not necessarily intended to reveal children's literal objective experience (which would be better captured using direct observational study combined with parent and teacher reports), but rather to explore children's meaning-making of their lives, including their responses to challenging situations. Thus, the children's narratives reflect perceptual, metaphorical and otherwise cognitively mediated experience that is nonetheless meaningful for the child, and which here we carefully attempt to consider possible interpretations for the current findings.

The high frequency of daily routines and concerns, including subthemes spontaneously provided by the child (e.g. school, money concerns) and contextual details of extending on specific subthemes first presented in some form in the story stem (e.g. mealtimes, household chores), strongly suggests that these children's responses are, in the most part, embedded in their lived experience. These descriptions of the 'world they know' include household duties, going to school, sharing meals, and leisure activities, 
the latter two sometimes sources of contention between child and caregiver. These subthemes may reflect children's own cognitive scripts and generalized memory representations on a psychological level and also cultural beliefs and ecological setting at a social level (Harwood et al. 1997; Weisner 1987, 2005). Children's education and healthy eating were also primary parental concerns echoed in Pelto and Armar-Klemesu (2011) study of parents in Accra.

Specific recurrent subthemes of daily routines and concerns emphasize the values of obedience, interdependence and cooperation in parenting and children (e.g. BoakyeBoaten 2010; Sam 2001) and economic concerns and aspirations (e.g. Ansong et al. 2018), consistent with prevailing beliefs and values in urban Ghana. The primary caregiver's role is described as one of high domestic obligation, while children are expected to contribute to household duties, which may be consistent with cultural values developed around economic and social need (Sam 2001; Owusu and Afutu-Kotey 2010). While children's assistance with housekeeping duties in the home and outside of it are essential for ensuring that the domestic unit functions effectively, they are also viewed as integral aspects of children's socialization process, character development, and application of values they need as future adults, such as responsibility and reciprocity. Children who depicted financial concerns, which Pelto and Armar-Klemesu (2011) found to also be of high parental concern, demonstrated an acute awareness of the scarcity of resources and the need to prioritize money for essential and educational needs over their own desires. Although at times showing distress over the inability to acquire material goods for themselves, overall they demonstrated understanding of the caregiver's rationale of prioritizing essential needs. In Ghanaian society, showing a sense of obligation to a larger set of other individuals and their needs is essential to children's socialization process (Oppong 2006). Yet, children's concerns may also be grounded in the real-life economic hardships faced by their families on a daily basis; recent Ghanaian statistics show that 36 percent of preschool children are malnourished, family financial status being a major determinant (Ewusie et al. 2017).

The notion of reciprocity bridges between other subthemes as well, including, adults' expectations of children, and children's understanding of these expectations. One of the fundamental underlying principles of reciprocity in Ghanaian society is the expectation that in the long run everyone is treated fairly in different phases of their lives (Boakye-Boaten 2010). Therefore, reciprocity plays a crucial role in intergenerational relationships that children themselves in our study emphasized the importance of values such as respect and obedience (Nyarko 2014). Reciprocity and obedience are very closely intertwined in Ghanaian society, as obedience is viewed a predeterminant to ensure that children's needs are provided for by adults (Ansong et al. 2018). Coe (2012) introduced the term 'entrustment' to explain this relationship between reciprocity, obligation, obedience in modern day Ghana; the act of being cared for obligates the child to reciprocate in a similar or other form of care in the future. Among children, this translates into being obedient and "doing household chores quickly and without fuss", as household chores are a commonly acknowledged responsibility for children in Ghana (Coe 2012). Twum-Danso Imoh's (2012, 2013) work revealed that children conveyed a fear that "if a child did not respect their parents, they may not pay school fees or even look after them or provide for their needs". Other work with Ghanaian parents reported that parents do not wish that their children view themselves as "entitled" to the care they receive from their parents, but would rather have them understand that care and services are earned through accepting and fulfilling their role and duties within their social context (Boakye-Boaten 2010; Twum-Danso 2009; Twum-Danso Imoh 2012, 2013). The current findings add a child perspective, evidencing that they understand the importance of obedience, and why disciplinary actions were taken when they knowingly or unknowingly did not submit to their caregiver's wishes.

Reciprocity of family support, or 'entrustment' (Cati Coe 2012), was also reflected in many children's narratives in which caregivers were supporting them financially as children, and that the child would later provide for their parents; this is highly valued in Ghanaian society (e.g. Ansong et al. 2018). In school-related subthemes, children stressed that the importance placed by their parents, and at times themselves, on education. This child perspective is mirrored in ethnographic observations and parental reports: due to the lack of effective social welfare system in Ghana, children's education is regarded as a form of security for the future of children and for providing better care of their elders (Therborn 2006; Twum-Danso 2009, Twum-Danso Imoh 2013). Conversations about school work are pervasive in child-caregiver interactions, as parents regard qualifications as directly associated with Ghanaian definitions of a more "successful life", which include as higher wages and social gains such as social cohesion, respect, and other health benefits (Coe 2012; Osei-Tutu et al. 2018)

Some narratives expressed high caregiver empathy in thoughts and feelings, even in situations of physical discipline, suggesting that story stems are a promising method for gaining insight into young children's understanding of others' empathy. However, explicitly expressed verbal or physical affection was less common than implicit forms; for example, caregivers showing affection through providing meals and children through helping with domestic duties or thinking how they would later provide for their family. This is echoed in other studies exploring parental affection 
expression and support in African and other non-Western contexts, in which instrumental support is considered by children to be a culturally-acknowledged form of affection (Barber and Higgins 2004; McNeely and Barber 2010; Mmari et al. 2009). Osei-Tutu et al. (2018) found that Ghanaian parents consider the ability to provide for their children financially as a sign of emotional care and that failure to do so is a form of emotional neglect.

On the other hand, caregiver-child interactions in a third of the current sample featured caregiver use of discipline, with expectations of compliance, and use of corporal punishment as an important feature of home life. Caregivers disciplined children for disobedient actions that were sometimes intentional, other times not clearly so, and this was nested within a general theme of expectations of the child role. Some children expressed helplessness. Nonetheless, these children generally construed the discipline as having a greater purpose of protection and learning. While caution must be taken when interpreting such themes literally, the literature suggests that use of physical discipline with children is commonplace in Ghana (Agbenyega 2006; Rush and Ibrahim Lazarus 2018) and is highly valued by most Ghanaians, guided by moral and religious imperatives (Twum-Danso Imoh 2013). Children at times reported being punished or reprimanded after injuring themselves during playtime. While this course of action may seem unusual in Western parenting practices, in Ghanaian culture great emphasis is placed on responsible action from an early age (Berlan 2004). Physical punishment after a child's injury during playtime might be viewed as the caregiver's way of providing protection via the virtues of obedience. Injury following play may be considered a disobedient act due to the irresponsibility of not exercising caution. Overall, the consistency of our findings with other literature on Ghanaian culture and child rearing practices, along with previous studies (e.g. Robinson et al. 2000), suggest that story stem assessment methods can provide a valuable window on caregiving techniques and goals through children's perspectives; such perspectives are grounded in realistic ecological circumstances.

The importance of socio-religious life was strongly reflected in young children's narratives, emerging as a theme in itself and also nested within 'daily routines and concerns' and 'death-relates fears and depictions' themes. Spiritual and religious attributions were common explanations for events, usually negative ones (Okyerefo and Fiaveh 2017). Spiritual acts and sentiments were employed to seek protection from threats or difficulties that were short-term (e.g. illness; school difficulties) or long-term (e.g. poverty). At times of distress children and their caregivers resorted to prayer together in the current sample's narratives. For some, this may be viewed as a coping mechanism and way of managing stress (Anyan and Knizek
2018), and may be adaptive if there are no viable problemfocused solutions. Children expressed that their caregiver's prayer had led to the immediate alleviation of a problem and protected them, suggesting that our sample may hold strong beliefs about the effectiveness of spiritual acts, such as praying, for alleviating various forms of distress. These findings are similar to those of Orme and Seipel's (2007) who found that young Ghanaian children actively gave credit to God for their well-being and protection. Osei-Tutu et al. (2018) also described that Ghanaian adults and children attribute their current and future successes to 'God's will' and that prayer is considered a means to reach this success. Children's expression of spirituality may also be a regurgitation of the religious values Ghanaian parents put conscious effort passing on to their children. Ghanaian parents describe their religious or spiritual beliefs as a source of guidance for their parenting beliefs and practices (Twum-Danso 2009). Previous studies reported that parents view instilling values of faith or religious traditions and practices as a parental obligation (Twum-Danso 2009; Twum-Danso Imoh 2013). However, while many themes are likely to reflect the child's perceptual experiences of everyday life, narratives that are emotionally loaded, involving chaotic or frightening circumstances, fantasies and idealizations, may be metaphorical and reflect the child's emotional landscape. Further, narrative responses to distressing circumstances, such as the use of prayer, are limited or determined by the child's understanding and perceptions of the situations at their current developmental level.

Death and hospitalization themes were a striking contrast to the themes that appeared grounded in everyday routine. Although the 'bad dream' stem scenario itself may arguably have prompted for negative events, the child is represented to have woken up already in the stem and is crying, with the caregiver sleeping in the adjacent room. Dreams and/or fears of abduction or murder following the nightmare were the most common context in which death themes occurred. Some children produced narratives in which a stomach pain or accidental injury (which was conveyed in the stem as neither serious nor prolonged) quickly descended to death or fears about dying. However, such findings need to be interpreted with care as children's understanding of death and illness is still developing at this age (Panagiotaki et al. 2015; Slaughter and Griffiths 2007) and narrative shifts made by children may reflect more the child's verbal and storytelling competence (or in the case of these stems, possibly arousal levels) than their cultural background or general developmental level. However, concerns about death may be interpreted to reflect cultural views of death, especially as Ghanaians are known for being deeply religious and "God fearing" (e.g. Okyerefo and Fiaveh 2017). A widespread belief is that misfortunes that occur are 
attributable to evil spirits or witchcraft, which may also manifest in dreams (Quayesi-Amakye 2017) or physical omens (Twum-Danso 2009; Dowden 2014). This interpretation may explain the prominence of spirituality as a content theme. However, another possibility is that the stem content of potentially fearful events triggered fears based on these children's lived experience in which premature death is a real possible outcome of illness, accidents and inability to pay for treatment (Affram et al. 2008). Consistent with this, one in twelve children die before their fifth birthday in Ghana, rates of childhood disease are high, and indices of child health are poor (Cooke et al. 2016; Ghana Statistical Service. 2014). A third, less culture-bound interpretation is that recurrent death and fears of death themes metaphorically represent aspects of the child's inner emotional experience. Death and accident themes has been associated with child clinical risk and problems in Western countries (Ispa et al. 2004; Tomlinson et al. 2002; Van Ijzendoorn and Sagi-Schwartz 2008; Wan and Green 2010). The actual meaning of such vivid content remains little empirically studied and may, for example, reflect the child's fears, aggression, emotional regulation difficulties, metaphorical usage, or relational issues.

\section{Strengths and Limitations}

This qualitative study has several strengths including the relatively large sample $(\mathrm{N}=69)$ representing a diverse socioeconomic spectrum within Ghana. Story stem content and language was adapted to fit local frames of reference and the local vernacular while retaining key scenario content in a standard manner, and interpretation of the data was enriched by a research team from a diverse cultural background. However, the findings must also be interpreted in view of several methodological considerations. Firstly, story stem content is likely to have influenced children's narrative content as the stems were originally designed to elicit attachment-related responses (Green et al. 2000). Each stem involved a child with a caregiver and the presentation of an enjoyable then distressing event. Thus, the 'addressing injuries' and 'spirituality' themes that emerged may reflect the sample's responses to negative events albeit of relatable situations in 'everyday' context.

Secondly, some children may have struggled to identify with the set-up or story beginnings despite the cultural and language adaptations made; for example, those living in of a single-room home may not relate to a multi-room home. Still, the MCAST which uses this set of stems has been found to work with a range of living arrangements. Thirdly, some children (mainly from the public school) provided narratives that were brief despite multiple prompts, perhaps due to a lack of proficiency or confidence with the English language (the official language used in schools), lack of clarity about the task requirement which may feel alien to children exposed to the didactic repetition methods typically used by Ghanaian schoolteachers (Akyeampong and Stephens 2002), lack of story-telling experience and/or verbal skill at their age (Nicolopoulou et al. 2015), or poverty as a similar study showed that children living in conditions of poverty showed more constricted narratives and less engagement than their peers (Castrechini Fernandes Franieck et al. 2014). Without further evidence, all these factors are plausible. Fourthly, videotaped doll play (or story depiction) was not analyzed here, which may have led to omission of more action-based details of children's stories. Finally, the analysis was completed by one researcher (the first author) and no reliability information is available, although supervised by a team of researchers with diverse (including qualitative) expertise.

\section{Implications and Future Directions}

Story stems have already been shown to be a flexible tool for understanding the inner worlds of young children in Western studies. Our qualitative use of story-stems in the Ghanaian context further demonstrates how young children's narratives derived from story stems can provide a 'window' into their life experiences, beliefs, coping strategies, emotions and empathic understanding-with narrative content that likely reflects a universal childhood and aspects that are more culture-specific. The current findings based on using the MCAST story stems suggest that the method could be clinically informative for gaining insight into children's understanding of healthcare, attributions of negative events, and use of coping strategies in children of non-Western cultural backgrounds. The findings also highlight the need to consider cultural background as a factor in the interpretation of story stem content of children living in multi-cultural Western societies. While the current study did not include a comparison sample through which to explore cultural contrasts, we note based on our experience that UK children's narratives tend to be flourished with detailed discourse between child and caregiver, include detailed and diverse descriptions of leisure time and friendships, possibly more expressed affection, and usually little in the way of family duty or spirituality. Although as we emphasize the study and findings do no attempt to make any cross-cultural comparisons, in this situation, given the dearth of literature on non-western samples, it could be argued that Western samples form an implicit comparison group.

Given the flexibility of the story stem technique, our findings suggest that there is much potential for its development for understanding the culturally mediated experiences, perceptions and emotional worlds of young children. Such developments include family stories using dolls to represent the child's full household, developing a range of story stem scenarios (e.g. some without an element of child distress) and thinking carefully about the appropriate 
amount of structure or level of apparent co-involvement from the administrator. Murray et al. (1999) employed a doll play task in which the administrator directly asked children to tell a story of a meal time, bed time, good time and nasty time. These kinds of scenarios could be modified into story stems. A stem brings the story to life, often compelling the child to complete the narrative, leading to more open responses in rapport with the administrator who may appear to be a 'co-creator' of the narrative.

Furthermore, a qualitative story stem approach would complement future sociocultural research involving homebased observations and caregiver reports. The latter two have the potential to offer insight on how to interpret children's story stem narratives, though we cannot assume that this would necessarily be so given that these various sources each offer unique perspectives. We hope that our study demonstrates the value and implications of exploring story stem narrative content in terms of complementing quantitative coding frameworks studying universal psychological constructs such as attachment; moreover in terms of guiding and incorporating children's perspectives into future interventions and prevention programmes designed for children and caregivers in diverse sociocultural settings (Robinson et al. 2000; Robinson 2007; Dealy et al. 2019).

To conclude, our novel, exploratory investigation supports utilising story-stem methodology in different cultural contexts to understand children's perspectives of their physical and social world (Bettmann and Lundahl 2007). It also suggests that exploring daily, cultural life through imaginative play narratives can provide in-depth understanding of cultural beliefs and constructs. Such explorations add to our understanding of children's perspectives of daily practices, health choices, discipline, interactions between child and caregiver, and spirituality in urban Ghana. More generally they also allow us to expand our conceptions of universal aspects of childhood. Literature addressing childhoods in Sub-Saharan Africa has mostly focused on challenges faced by children, which does not portray a balanced image of childhoods in Africa (TwumDanso Imoh 2016). Our investigation attempts to provide a balanced image of children's perceptions of their own lives in a West-African Nation, that is not confined to only exploring aspects of hardship and deprivation in their childhoods, but also to incorporate the mundanities of their daily lives.

Funding University of Manchester

\section{Compliance with Ethical Standards}

Conflict of Interest The authors declare that they have no conflict of interest.
Informed Consent This study is a retrospective study, and hence no additional formal consent is required. At the time of the of data collection for the previous study informed consent was obtained from all individual the legal guardians of participants included in the study.

Publisher's note Springer Nature remains neutral with regard to jurisdictional claims in published maps and institutional affiliations.

Open Access This article is licensed under a Creative Commons Attribution 4.0 International License, which permits use, sharing, adaptation, distribution and reproduction in any medium or format, as long as you give appropriate credit to the original author(s) and the source, provide a link to the Creative Commons license, and indicate if changes were made. The images or other third party material in this article are included in the article's Creative Commons license, unless indicated otherwise in a credit line to the material. If material is not included in the article's Creative Commons license and your intended use is not permitted by statutory regulation or exceeds the permitted use, you will need to obtain permission directly from the copyright holder. To view a copy of this license, visit http://creativecommons. org/licenses/by/4.0/.

\section{References}

Adzahlie-Mensah, V. (2014). Being 'Nobodies': School Regimes and Student Identities in Ghana. Unpublished doctoral Thesis. Brighton: University of Sussex. http://sro.sussex.ac.uk/id/eprint/ 48419/.

Affram, C. K., Laryea, J., Allen, M., \& Oliver-Commey, J. O. (2008). The experiences of mothers with children hospitalised in a children's emergency unit, Ghana. Africa. Journal of Nursing and Midwifery, 10(1), 44-58.

Agbenyega, J. S. (2006). Corporal punishment in the schools of Ghana: does inclusive education suffer? The Australian Educational Researcher, 33(3), 107-122.

Akyeampong, K., \& Stephens, D. (2002). Exploring the backgrounds and shaping of beginning student teachers in Ghana: toward greater contextualisation of teacher education. International Journal of Educational Development, 22(3), 261-274.

Allen, B., Bendixsen, B., Babcock Fenerci, R., \& Green, J. (2018). Assessing disorganized attachment representations: a systematic psychometric review and meta-analysis of the Manchester Child Attachment Story Task. Attachment \& Human Development, 23, $1-25$.

Ansong, D., Okumu, M., Hamilton, E. R., Chowa, G. A., \& Eisensmith, S. R. (2018). Perceived family economic hardship and student engagement among junior high schoolers in Ghana. Children and Youth Services Review, 85, 9-18.

Anyan, F., \& Knizek, B. L. (2018). The coping mechanisms and strategies of hypertension patients in Ghana: the role of religious faith, beliefs and practices. Journal of Religion and Health, 57, $1402-1412$.

Arku, G., Luginaah, I., Mkandawire, P., Baiden, P., \& Asiedu, A. B. (2011). Housing and health in three contrasting neighbourhoods in Accra, Ghana. Social Science \& Medicine, 72(11), 1864-1872.

Arsenio, W., \& Ramos-Marcuse, F. (2014). Children's moral emotions, narratives, and aggression: relations with maternal discipline and support. The Journal of Genetic Psychology, 175(6), $528-546$.

Barber, B. K., \& Higgins, W. B. (2004). The connection with adult caregiver tool: Statistical analyses of data from adolescents in Malawi and Jamaica (Report to UNICEF). Washington, DC: UNICEF. 
Batki, A. (2018). The impact of early institutional care on emotion regulation: studying the play narratives of post-institutionalized and early adopted children. Early Child Development and Care, $188,1-15$.

Berlan, A. (2004). Child labour, education and child rights among cocoa producers in Ghana. In C. Van den Anker (Ed.), The political economy of new slavery (pp. 158-178). London: Palgrave Macmillan.

Bettmann, J. E., \& Lundahl, B. W. (2007). Tell me a story: a review of narrative assessments for preschoolers. Child and Adolescent Social Work Journal, 24(5), 455-475.

Boakye-Boaten, A. (2010). Changes in the concept of childhood: implications on children in Ghana. Journal of International Social Research, 3(10), 104-115.

Braun, V., \& Clarke, V. (2006). Using thematic analysis in psychology. Qualitative Research in Psychology, 3(2), 77-101.

Braun, V., Clarke, V., \& Gray, D. (2017). Innovations in qualitative methods. In The Palgrave handbook of critical social psychology (pp. 243-266). London: Palgrave Macmillan.

Castrechini Fernandes Franieck, M. L., Günter, M., \& Page, T. (2014). Engaging Brazilian street children in play: observations of their family narratives. Child Development Research, 2014, 861703.

Castrechini Fernandes Franieck, M. L., \& Page, T. (2017). The family narratives of three siblings living in a 'street situation' since birth. Early Child Development and Care, 189, 1575-1587.

Clarke, V., Hayfield, N., Moller, N., \& Tischner, I. (2017). Once upon a time...Qualitative story completion methods. In V. Braun, V. Clarke \& D. Gray (Eds), Collecting qualitative data: a practical guide to textual, media and virtual techniques (pp. 45-70). Cambridge: Cambridge University Press.

Coe, C. (2012). Growing Up and Going Abroad: How Ghanaian Children Imagine Transnational Migration. Journal of Ethnic and Migration Studies, 38, 913-931.

Coe, J. L., Davies, P. T., \& Sturge-Apple, M. L. (2017). Family instability and young children's school adjustment: callousness and negative internal representations as mediators. Child Development., 89, 1-16.

Cooke, E., Hague, S., \& McKay, A. (2016). The Ghana poverty and inequality report: using the 6th Ghana living standards survey. University of Sussex. http://africainequalities.org/w pcontent/uploads/2016/07/Ghana_Poverty_and_Inequality_ Analysis_FINAL_Match_20161.pdf.

Dealy, J., Mudrick, H., \& Robinson, J. (2019). Children's narrative story stem responses: contributions of executive functioning and language proficiency to relationship representations. Social Development, 28(1), 168-185.

Dowden, R. (2014). Africa: altered states, ordinary miracles. London: Granta.

Ewusie, J. E., Beyene, J., Ahiadeke, C., \& Hamid, J. S. (2017). Malnutrition in pre-school children across different geographic areas and socio-demographic groups in Ghana. Maternal and Child Health Journal, 21(4), 797-808.

Ghana Statistical Service. (2014). Population projection by sex, 2010 to 2014, National Statistical Service. Ghana Statistical Service. http://www.statsghana.gov.gh/.

Green, J., Stanley, C., Smith, V., \& Goldwyn, R. (2000). A new method of evaluating attachment representations in young schoolage children: the Manchester Child Attachment Story Task. Attachment \& Human Development, 2(1), 48-70.

Guest, G., MacQueen, K. M., \& Namey, E. E. (2011). Applied thematic analysis. London: Sage.

Fink, G., Weeks, J. R., \& Hill, A. G. (2012). Income and Health in Accra, Ghana: Results from a Time Use and Health Study. The American Journal of Tropical Medicine and Hygiene, 87(4), 608-615.
Harwood, R. L., Miller, J. G., \& Irizarry, N. L. (1997). Culture and attachment: perceptions of the child in context. New York: Guilford Press.

Ispa, J. M., Fine, M. A., Halgunseth, L. C., Harper, S., Robinson, J., Boyce, L., \& Brady- Smith, C. (2004). Maternal intrusiveness, maternal warmth, and mother-toddler relationship outcomes: variations across low-income ethnic and acculturation groups. Child Development, 75(6), 1613-1631.

Joffe, H. (2012). Thematic analysis. In D. Harper \& A. R. Thompson (Eds), Qualitative research methods in mental health and psychotherapy: a guide for students and practitioners (pp. 210-223). Chichester: Wiley-Blackwell.

Keller, H., \& Kärtner, J. (2013). The cultural solution of universal developmental tasks. Advances in Culture and Psychology, 3, 63-116.

Kuyini, A. B., Alhassan, A. R., Tollerud, I., Weld, H., \& Haruna, I. (2009). Traditional kinship foster care in northern Ghana: the experiences and views of children, carers and adults in Tamale. Child \& Family Social Work, 14(4), 440-449.

Lansdown, G. (2004). Participation and young children. Early Childhood Matters, 103, 4-14.

McCullough, D., Hatipoglu, K., \& Burnett, N. (2015). "Free" government schools and low cost private schools: What households really spend on education in Kasoa, Ghana. Prepared by Results for Development Institute for the IJBS Optimus Foundation. Retrieved on 7 October 2020 from https://r4d.org/resources/exploring-public-and-private-educa tion-costs-ghana/.

McNeely, C. A., \& Barber, B. K. (2010). How do parents make adolescents feel loved? Perspectives on supportive parenting from adolescents in 12 cultures. Journal of Adolescent Research, 25 (4), 601-631.

Milojevich, H. M., \& Quas, J. A. (2017). Parental attachment and children's memory for attachment-relevant stories. Applied Developmental Science, 21(1), 14-29.

Mmari, K., Michaelis, A., \& Kiro, K. (2009). Risk and protective factors for HIVamong orphans and non-orphans in Tanzania. Culture, Health, and Sexuality, 11(8), 799-806.

Murray, L., Woolgar, M., Briers, S., \& Hipwell, A. (1999). Children's social representations in dolls' house play and theory of mind tasks, and their relation to family adversity and child disturbance. Social Development, 8(2), 179-200.

Nicolopoulou, A., Cortina, K. S., Ilgaz, H., Cates, C. B., \& de Sá, A. B. (2015). Using a narrative-and play-based activity to promote low-income preschoolers' oral language, emergent literacy, and social competence. Early Childhood Research Quarterly, 31, $147-162$.

Nyarko, K. (2014). Childrearing, motherhood and fatherhood in Ghana. In H. Selin (Ed.), Parenting across cultures. science across cultures: the history of non-western science 7, Dordrecht: Springer.

Okyerefo, M. P. K., \& Fiaveh, D. Y. (2017). Prayer and health-seeking beliefs in Ghana: understanding the 'religious space' of the urban forest. Health Sociology Review, 26(3), 308-320.

Oppong, C. (2006), Demographic innovation and nutritional catastrophe: change, lack of change and difference in Ghanaian family systems. In G. Therborn (Ed.), African familiesin in a global context. Uppsala: Nordiska Afrikainstitutet.

Orme, J., \& Seipel, M. M. (2007). Survival strategies of street children in Ghana: a qualitative study. International Social Work, 50(4), 489-499.

Osei-Tutu, A., Dzokoto, V. A., Adams, G., Hanke, K., KwakyeNuako, C., Adu-Mensa, F., \& Appiah- Danquah, R. (2018). 'My own house, car, my husband, and children': meanings of success among Ghanaians. Heliyon, 4(7), e00696. 
Owusu, G., \& Afutu-Kotey, R. L. (2010). Poor urban communities and municipal interface in Ghana: a case study of Accra and SekondiTakoradi metropolis. African Studies Quarterly, 12(1), 1.

Panagiotaki, G., Nobes, G., Ashraf, A., \& Aubby, H. (2015). British and Pakistani children's understanding of death: cultural and developmental influences. British Journal of Developmental Psychology, 33(1), 31-44.

Pelto, G. H., \& Armar-Klemesu, M. (2011). Balancing nurturance, cost and time: complementary feeding in Accra, Ghana. Maternal \& Child Nutrition, 7, 66-81.

Plokar, A., Bisaillon, C., \& Terradas, M. M. (2017). Development of the child dissociation assessment system using a narrative story stem task: a preliminary study. European Journal of Trauma \& Dissociation. 2, 21-19.

Quayesi-Amakye, J. (2017). 'Maame, you are a witch': an inquiry into the phenomenon of witchcraft in Ghanaian socio-religious life. Conspectus, 24, 165-183.

Quist, H. O. (2003). Secondary education: a 'tool' for national development in Ghana. a critical appraisal of the post-colonial context. Africa Development, 28(3-4), 186-210.

Republic of Ghana Ministry of Education (2013). Education Sector Performance Report. Retrieved on 7 October 2020 from https:// new-ndpc-static1.s3.amazonaws.com/pubication/2012+Educa tion + Sector + Performance + Report.pdf.

Robinson, J., Hérot, C., Haynes, P., \& Mantz-Simmons, L. (2000). Children's story stem responses: a measure of program impact on developmental risks associated with dysfunctional parenting. Child Abuse \& Neglect, 24(1), 99-110.

Robinson, J. L. (2007). Story stem narratives with young children: moving to clinical research and practice. Attachment \& Human Development, 9(3), 179-185.

Rush, M., \& Ibrahim Lazarus, S. (2018). 'Troubling' chastisement: a comparative historical analysis of child punishment in Ghana and Ireland. Sociological Research Online, 23(1), 177-196.

Sam, D. L. (2001). Value of children: effects of globalization on fertility behaviour and child-rearing practices in Ghana. Institute of African Studies Research Review, 17(2), 5-16.

Slaughter, V., \& Griffiths, M. (2007). Death understanding and fear of death in young children. Clinical Child Psychology and Psychiatry, 12, 525-535.

Tamis-LeMonda, C. S., Way, N., Hughes, D., Yoshikawa, H., Kalman, R. K., \& Niwa, E. Y. (2008). Parents' goals for children: the dynamic coexistence of individualism and collectivism in cultures and individuals. Social Development, 17(1), 183-209.

Therborn, G. (2006), African families in a global context. In G. Therborn (Ed.), African families in a global context. Uppsala: Nordiska Afrika institutet.

Tomlinson, M., Cooper, P., Swartz, L., \& Molteno, C. (2002). Challenges in assessing attachment and associated factors in a South
African peri-urban settlement. In 8th World Association for Infant Mental Health World Congress, Amsterdam.

Twum-Danso, A. (2009). Reciprocity, respect and responsibility: the 3Rs underlying parent-child relationships in Ghana and the implications for children's rights. The International Journal of Children's Rights, 17(3), 415-432.

Twum-Danso Imoh A. (2012) Cultural practices in the face of globalized ideals: the case of physical punishment of children in Ghana. In A. Twum-Danso Imoh \& R. Ame (Eds), Childhoods at the intersection of the local and global. Basingstoke: Palgrave.

Twum-Danso Imoh, A. (2013). Children's perceptions of physical punishment in Ghana and the implications for children's rights. Childhood, 20(4), 472-486.

Twum-Danso Imoh, A. (2016). From the singular to the plural: exploring diversities in contemporary childhoods in sub-Saharan Africa. Childhood, 23(3), 455-458. https://doi.org/10.1177/ 0907568216648746.

United Nations Department of Economic and Social Affairs (2019). World Population Prospects (2019 revision). United Nations, New York. Retrieved on 8 October 2020 from https://population. un.org/wpp/Publications/.

Wan, M. W., Danquah, A. N., \& Mahama, S. (2017). Child-caregiver attachment representations in a non-western context: the feasibility and cultural equivalence of story stems in urban Ghana. Social Development, 26(1), 59-79.

Wan, M. W., \& Green, J. (2010). Negative and atypical story content themes depicted by children with behaviour problems. Journal of Child Psychology and Psychiatry, 51(10), 1125-1131.

Weisner, T. S. (1987). Socialization for parenthood in sibling caretaking societies. In T. S. Weisner (Ed.), Parenting across the life span: biosocial dimensions (pp. 237-270). New York: Aldine Press.

Weisner, T. S. (2005). Attachment as a cultural and ecological problem with pluralistic solutions. Human Development, 48(1-2), 89-94.

Winter, M. A., Fiese, B. H., Spagnola, M., \& Anbar, R. D. (2011). Asthma severity, child security, and child internalizing: using story stem techniques to assess the meaning children give to family and disease-specific events. Journal of Family Psychology, 25(6), 857-867.

Van Ijzendoorn, M. H., \& Sagi-Schwartz, A. (2008). Cross-cultural patterns of attachment: universal and contextual dimensions. In J. Cassidy \& P. R. Shaver (Eds), Handbook of attachment: theory, research, and clinical applications (pp. 880-905). New York: Guilford Press.

Yuval-Adler, S., \& Oppenheim, D. (2015). Story completion play narrative methods for preschool children. In O. Saracho (Ed.), Handbook of research method in early childhood education (pp. 323-381). Charlotte, NC: Information Age Publishing. 